\section{MRS's Other Meetings}

When our members think of the Materials Research Society, they think first of our spring and fall meetings in San Francisco and Boston, respectively. These are our "prime products" in the business of information exchange, and most of you regard our publications-especially $M R S$ Bulletin, the Journal of Materials Research, and the MRS proceedings-as the complement to the meetings. I will write more about the publications later in the year, but it is timely to discuss some of our mer, roughly halfway between the "main" MRS meetings.

Feedback on the spring and fall meetings tells us that they meet real needs, but also that they are not all things to all people, and they cannot expand to become that. They are aggressively focused on leading-edge research and broad, interdisciplinary programming. There is a need, however, for more focused, less highly structured meetings within many of the subject areas in which MRS has a clear strength and a high profile. To meet these needs, we support a number of additional meetings each year. These range from collaborative ventures with other societies to our own workshop series. Look for these during the summer doldrums if you need a "meeting fix."

MRS welcomes the opportunity to cooperate with other technical societies and organizations in co-sponsorships and endorsements of our own technical symposia or meetings held by others. Such cooperation enables MRS to expand the scope of its programming, avoid duplication of technical topics, enhance the interdisciplinary environment, and aid the dissemination of materials research results. The benefits include wider notification of symposium topics, scope, and focus; increased awareness of each organization's activities and publications; and identification of researchers with specific interests.

MRS workshops are stand-alone, single-topic meetings, usually with an attendance of $\sim 100$ and conducted in various locations, typically in a hotel or a dedicated small conference facility. They are intended to promote extensive discussion and are typically programmed with long talks and ample time for question-andanswer sessions and roundtable discussions. There are no parallel symposia competing for the participants' attention. Unlike the regular MRS meetings, some meals are included in the registration, so the participants socialize together to proother meeting activities held in the sum-

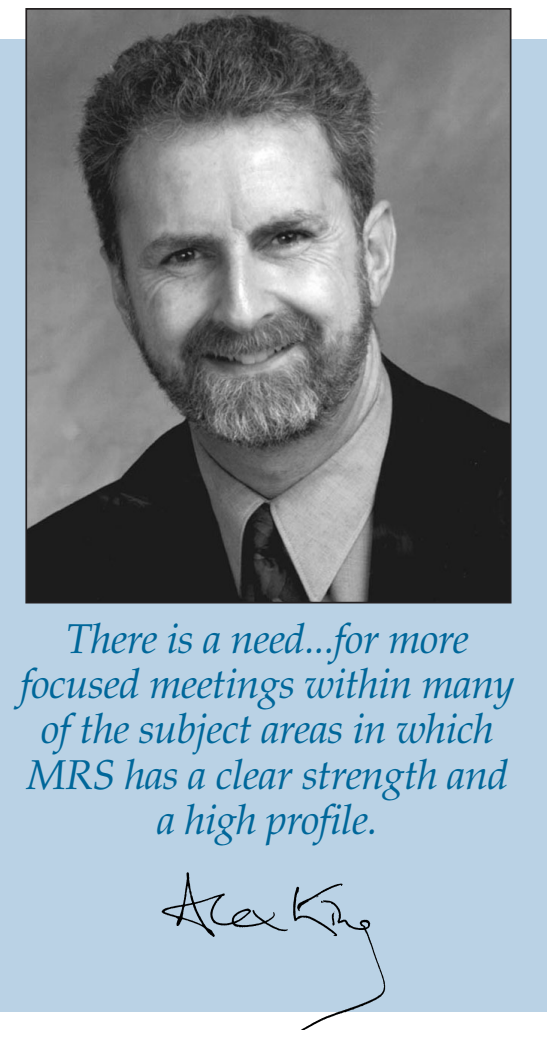

mote discussion. Workshops may be organized jointly with other societies, and a number are already being developed with European-MRS.

Workshops can be organized on topics that may not be at the "cutting edge" as defined by current symposium topics at the spring or fall meetings; they can rather focus on materials that are in transition to industrial application, as many of us address the issue of shortening the time from discovery to use. In other cases, workshops are organized to allow for a less "polished" and more open discussion than a symposium presentation calls for, allowing problem areas to be addressed more openly. An interesting and very successful example of this type of workshop was held earlier this year: A workshop on microelectromechanical systems (MEMS) was held immediately after the 2002 MRS Spring Meeting in San Francisco, where there was also a "traditional" symposium on MEMS and BioMEMS. Those who attended both found that there were distinct benefits to be drawn from the two types of meetings: New results were presented as papers in the symposium, and problem areas such as characterization, durability, and standardization were discussed in the workshop (see the workshop report in the June 2002 issue of MRS Bulletin).

Planned for this year are the International Workshop on Processing and Applications of Superconductors, August 1-2 in Gatlinburg, Tenn.; and the 2nd International Workshop on Zinc Oxide, October 23-25 in Dayton, Ohio. More workshops are also in development.

The workshop program is still new, and like all MRS activities, it is assertively experimental: We will refine it and adapt it to new circumstances as opportunities arise and demands occur. Keep an eye open for workshops that are of interest to you, and be assured that they will be very different from regular MRS meetings, but still organized with the same quality that you have come to expect from the Society. If you have an idea for a workshop generally fitting the description here, contact Patricia Hastings (hastings@mrs.org) at MRS Headquarters to discuss the possibility of organizing it. We are especially interested in ideas from industry-based members and are very willing to work with you to develop preliminary ideas into well-rounded meetings.

Endorsed meetings, sponsored meetings, and workshops will not take the place of the regular MRS meetings, but they will complement them and provide opportunities for different kinds of exchange that are of high value to our members. I hope you will participate.

Alex KING

2002 MRS President

\section{Upcoming 2002 Materials Research Society Workshops /www.mrs.org/meetings/workshops/}

- International Workshop on Processing and Applications of Superconductors August 1-2, 2002, Gatlinburg, Tennessee, USA

- 2nd International Workshop on Zinc Oxide October 23-25, 2002 , Dayton, Ohio, USA

To suggest a topic or volunteer to organize a workshop,

contact Patricia Hastings, Director of Meeting Activities, Materials Research Society, 506 Keystone Drive, Warrendale, PA 15086-7573, USA; tel. 724-779-3004 ext. 350; fax 724-779-8313; or hastings@mrs.org. 